\title{
Voltammetric determination of ascorbic acid in the presence of acetaminophen and tryptophan using an improved carbon nanotube paste electrode
}

\author{
Hadi BEITOLLAHI ${ }^{a, *}$, Somayeh MOHAMMADI ${ }^{b}$ \\ a Environment Department, Institute of Science and High Technology and Environmental Sciences, Graduate University of Advanced Technology, Kerman, \\ Iran \\ b Department of Chemistry, Payame Noor University, 19395-4697, Tehran, Iran
}

\section{A R T I C L E I N F O}

Article history:

Received 4 November 2012

Accepted 31 January 2013

Published 20 June 2013

\section{Keywords:}

Ascorbic acid

Acetaminophen

Tryptophan

Carbon nanotube paste electrode

Electrocatalysis

\author{
A B S T R A C T
}

A carbon paste electrode (CPE) modified with carbon nanotubes and 5-amino-3',4'-dimethyl- biphenyl-2-ol (5ADB) is prepared. Under the optimum $\mathrm{pH}$ of 7.0, the oxidation of ascorbic acid (AA) on the modified CPE occurs at a potential about $280 \mathrm{mV}$ less positive than that on the unmodified CPE. Some kinetic and thermodynamic parameters for electrocatalytic oxidation of AA, including electron transfer coefficient $(\alpha=0.58)$ and diffusion coefficient $\left(D=2.2 \times 10^{-6} \mathrm{~cm}^{2} / \mathrm{s}\right)$, are also determined. AA, acetaminophen (AC), and tryptophan (TRP) were detected simultaneously using the modified CPE. The peak potentials recorded using the modified CPE in phosphate-buffered solution at pH 7.0 were 265,465 , and $780 \mathrm{mV}$ for AA, AC, and TRP, respectively. The modified CPE was successfully used to determine the concentrations of $\mathrm{AA}, \mathrm{AC}$, and TRP in real samples.

(c) 2013, Dalian Institute of Chemical Physics, Chinese Academy of Sciences. Published by Elsevier B.V. All rights reserved.

\section{Introduction}

Electrochemical methods have traditionally been applied in sample analysis and organic and inorganic synthesis because of their low cost, ease of use, and reliability [1,2]. Most recent developments in electroanalytical chemistry include advances in sensor design, chemical modification, and functionalization of electrodes for enhanced sensitivity and selectivity [3]. Electrochemical methods using chemically modified electrodes (CMEs) have been widely used for sensitive and selective detection of trace amounts of important biological compounds, particularly for vitamins such as ascorbic acid (vitamin C, AA) [4-7]. CMEs can catalyze the electrode process at significantly lower overpotential through the selective interaction of an electron mediator with a target analyte $[8,9]$.

Since the discovery of carbon nanotubes (CNTs) in 1991
[10], their properties and applications have been investigated extensively. CNTs are important nanomaterials because of their high chemical stability and surface area, excellent mechanical properties, unique electrical conductivity, and metallic structural characteristics. Their special tube structure endows CNTs with these unique properties. In addition, the subtle electronic behavior of CNTs means that they have the ability to promote electron transfer reactions, and have a strong electrocatalytic effect when used as electrode materials [11-17].

AA is a six-carbon lactone that is synthesized from glucose in the liver of most mammalian species except humans [18]. AA is an electron donor, and this property accounts for all of its known functions, including acting as a potent water-soluble antioxidant in humans [19]. AA is present in many biological systems and multivitamin preparations. It is commonly used to prevent and treat the common cold, mental illness, infertility,

*Corresponding author. Tel: +98-342-6226613; Fax: +98-342-6226617; E-mail: h.beitollahi@yahoo.com 
cancer, photoaging, skin disorders, and AIDS [20,21]. Therefore, detecting and determining the concentration of $\mathrm{AA}$ in samples are of great importance for pharmaceutical, clinical, and food industries. To date, many methods have been used to detect AA including spectroscopy [22], enzymatic analysis [23], and electrochemistry [24]. Importantly, AA is electroactive at carbon and platinum electrodes. However, its oxidation requires undesirably high overvoltages. To improve the sensitivity and selectivity of AA detection, the operating potentials should be lowered and the oxidation currents should be increased. This can be achieved by modifying the surface of electrodes with suitable electrocatalysts [25-27].

Acetaminophen ( $\mathrm{N}$-acetyl-P-aminophenol or paracetamol, AC) is a common antipyretic and analgesic drug typically used to reduce mild to moderate pain or fever [28]. It is frequently recommended when aspirin may present problems to a patient, particularly in pediatrics or after surgery [28]. Ingestion of excess AC causes toxic metabolites to accumulate, which may cause severe and sometimes fatal hepatotoxicity and nephrotoxicity, and in some cases, renal failure [29]. Until 2010, AC was believed safe in pregnancy. However, a recent study linked it to infertility in adults exposed to AC as fetuses [30]. Many methods have been used to determine the concentration of AC, such as titrimetry, spectrophotometry, flow injection, and chromatography. Electrochemical methods have also been used extensively because of their elegance and sensitivity [31-36]. Tryptophan (TRP) is one of the 20 standard amino acids, and is essential in many organisms, including humans. TRP cannot be synthesized by organisms, so it must be part of their diet. TRP is a building block in protein biosynthesis, and also functions as a biochemical precursor for biologically important molecules, such as the neurotransmitter serotonin and the neurohormone melatonin [37]. It has been reported that inadequate serotonin and melatonin levels in human brains are partially responsible for depression [38], and Alzheimer's and Parkinson's diseases [39], respectively. TRP is currently prescribed for a wide range of disorders including anxiety, insomnia, addiction, and obesity. As a result, analysis of TRP is of great importance in the fields of biochemistry, pharmaceuticals, and dietetics. Methods to determine the concentration of TRP are mainly based on HLPC and spectrophotometry, although electroanalytical methods have received interest in recent years because of their sensitivity, accuracy, and simplicity [40-43].

The adjunct presence of AA with AC increases the positive effects of AC and decreases its toxicity $[19,44]$. High doses of AA may lower the amount of AC passed in urine, which could cause the level of this drug in blood to rise [45]. Lactose and AA are not contaminated by TRP when used as anti-oxidizing reagents. Both improve TRP recovery, but AA is more effective [46]. Therefore, determination of these compounds in the presence of each other is important. However, most previous electrochemical studies have only considered individual determination of AA, AC, and TRP, or with other substrates. A single study has reported the simultaneous determination of $\mathrm{AA}, \mathrm{AC}$, and TRP using a modified carbon nanotube paste electrode (CNPE) [24]. In the present work, we prepare a novel electrode com- posed of a CNPE modified with 5-amino-3',4'-dimethyl- biphenyl-2-ol (5ADB-CNPE), and investigate its performance for the electrocatalytic determination of $\mathrm{AA}$ in aqueous solution. We also evaluate the analytical performance of the modified electrode for quantification of $\mathrm{AA}$ in the presence of $\mathrm{AC}$ and TRP.

\section{Experimental}

\subsection{Apparatus and chemicals}

Electrochemical measurements were performed with an Autolab potentiostat/galvanostat (PGSTAT 12, Eco Chemie, The Netherlands). Experimental conditions were controlled with General Purpose Electrochemical System (GPES) software. A conventional three electrode cell was used at $(25 \pm 1){ }^{\circ} \mathrm{C}$. An $\mathrm{Ag} / \mathrm{AgCl} / \mathrm{KCl}$ (3.0 mol/L) electrode, platinum wire, and 5ADB-CNPE were used as the reference, auxiliary, and working electrodes, respectively. $\mathrm{pH}$ was monitored with a $\mathrm{pH} /$ ion meter (Metrohm 827).

All solutions were freshly prepared with double distilled water. AA, AC, TRP, and all other reagents were of analytical grade and were purchased from Merck (Darmstadt, Germany). Graphite powder and paraffin oil (DC 350, density $=0.88$ $\mathrm{g} / \mathrm{cm}^{3}$ ) as binding agents (both from Merck) were used to prepare pastes. Multi-walled CNTs (purity > 95\%) with outer and inner diameters of 10-20 and 5-10 nm, respectively, and lengths of $0.5-200 \mu \mathrm{m}$ were purchased from Nanostructured \& Amorphous Materials, Inc. Buffer solutions were prepared from orthophosphoric acid and its salts in the $\mathrm{pH}$ range of 2.0-9.0.

\subsection{Synthesis of $5 A D B$}

To prepare 5ADB, $N$-(2-hydroxy-phenyl)-acetamide (3.02 g, 20 mmol), 4-bromo-o-xylene (3.70 g, $20 \mathrm{mmol})$, and $\mathrm{PdCl}_{2}\left(\mathrm{PPh}_{3}\right)_{4}(2.81 \mathrm{~g})$ were added to a mixture of dimethylacetamide $(20 \mathrm{ml})$ and $t$-BuOK $(6.72 \mathrm{~g})$. The mixture was stirred and heated at about $90{ }^{\circ} \mathrm{C}$ for $12 \mathrm{~h}$. The progress of the reaction was monitored by TLC. After completion of reaction, the resulting mixture was allowed to cool for a few minutes, and then $\mathrm{Pd}\left(\mathrm{PPh}_{3}\right)_{4}$ was collected by vacuum filtration using a Hirsch funnel. Chloroform was added to the mixture, which was then filtered to recover the catalyst. The resulting acetamide was readily cleaved by barium hydroxide with a yield of $>90 \%$. The crude product was recrystallized from isopropanol and chloroform $(20: 80)$ to afford 5ADB in $83 \%$ yield.

\subsection{Preparation of $5 A D B-C N P E$}

5ADB-CNPE was prepared by mixing 5ADB (0.01 g) with graphite powder $(0.89 \mathrm{~g})$ and CNTs $(0.1 \mathrm{~g})$ using a mortar and pestle. Paraffin oil ( $\sim 0.7 \mathrm{ml})$ was added and the mixture was ground for $20 \mathrm{~min}$ until a uniform paste was obtained. The paste was packed into the end of a glass tube with an internal diameter of $3.4 \mathrm{~mm}$ and length of $15 \mathrm{~cm}$. A copper wire was inserted into the carbon paste as an electrical contact. When necessary, a new surface was obtained by pushing some of the 
paste out of the tube and polishing the end with weighing paper.

For comparison, a 5ADB-modified CPE lacking CNTs (5ADB-CPE), a CNPE lacking 5ADB, and an unmodified CPE lacking both $5 \mathrm{ADB}$ and CNTs were also prepared in the same manner.

\section{Results and discussion}

\subsection{Electrochemical properties of $5 A D B-C N P E$}

The electrochemical properties and, in particular, the electrocatalytic activity of 5ADB in aqueous media have not been reported. Therefore, we studied the electrochemical properties of 5ADB-CNPE in phosphate-buffered solution (PBS) at $\mathrm{pH} 7.0$ using cyclic voltammetry (CV), as shown in Fig. 1 . One of the advantages of $5 \mathrm{ADB}$ as an electrode modifier is its insolubility in aqueous media. 5ADB-CNPE exhibited reproducible, well-defined anodic, and cathodic peaks with $E_{\mathrm{pa}}, E_{\mathrm{pc}}$, and $E^{\circ \prime}$ of $0.28,0.18$, and $0.23 \mathrm{~V}$ vs. $\mathrm{Ag} / \mathrm{AgCl} / \mathrm{KCl}(3.0 \mathrm{~mol} / \mathrm{L})$, respectively. The observed peak separation potential $\Delta E_{\mathrm{p}}\left(=E_{\mathrm{pa}}-E_{\mathrm{pc}}\right)$ of $100 \mathrm{mV}$, was greater than the value of $59 / \mathrm{n} \mathrm{mV}$ expected for a reversible system [47], suggesting that the redox couple of $5 A D B$ in 5ADB-CNPE shows quasi-reversible behavior in an aqueous medium. The effect of the potential scan rate $(v)$ on the electrochemical properties of 5ADB-CNPE was also studied by CV. Plots of both the anodic and cathodic peak currents $\left(I_{\mathrm{p}}\right)$ depended linearly on $v$ in the range of 10 to $800 \mathrm{mV} / \mathrm{s}$ (Fig. 1(b)), indicating that the redox process of 5ADB at the modified electrode is diffusionless.

The apparent charge transfer rate constant, $k_{\mathrm{s}}$, and charge transfer coefficient, $\alpha$, of a surface-confined redox couple can be determined from $\mathrm{CV}$ experiments using the variation of anodic and cathodic peak potentials with logarithm of scan rate according to the procedure of Laviron [48]. Figure 1(c) shows such plots, indicating that $E_{\mathrm{p}}$ is proportional to the logarithm of scan rate for $v$ higher than $3 \mathrm{~V} / \mathrm{s}$. The slopes of the plots in Fig. 1(c) can be used to extract the kinetic parameters $\alpha_{\mathrm{c}}$ and $\alpha_{\mathrm{a}}$ (cathodic and anodic transfer coefficients, respectively). The slopes of the linear segments are equal to $-2.303 R T / \alpha n F$ and $2.303 R T /(1-\alpha) n F$ for the cathodic and anodic peaks, respectively, so $\alpha=0.5$.

Equation (1) can be used to determine the electron transfer rate constant between the modifier (5ADB) and CNPE:

$$
\begin{aligned}
\log k_{\mathrm{s}} & =\alpha \log (1-\alpha)+(1-\alpha) \log \alpha-\log (R T / n F v) \\
& -\alpha(1-\alpha) n F \Delta E_{\mathrm{p}} / 2.3 R T
\end{aligned}
$$

where $(1-\alpha) n_{\alpha}=0.5, v$ is the sweep rate, and all other symbols have their conventional meanings. $k_{\mathrm{s}}$ was calculated to be 23.9 $\mathrm{s}^{-1}$ using Eq. (1).

\subsection{Influence of $p H$}

The electrochemistry of 5ADB is generally $\mathrm{pH}$ dependent, so the electrochemical behavior of 5ADB-CNPE was studied at different pH using CV (Fig. 2(a)). The anodic and cathodic peak potentials of 5ADB-CNPE shifted to less positive values with
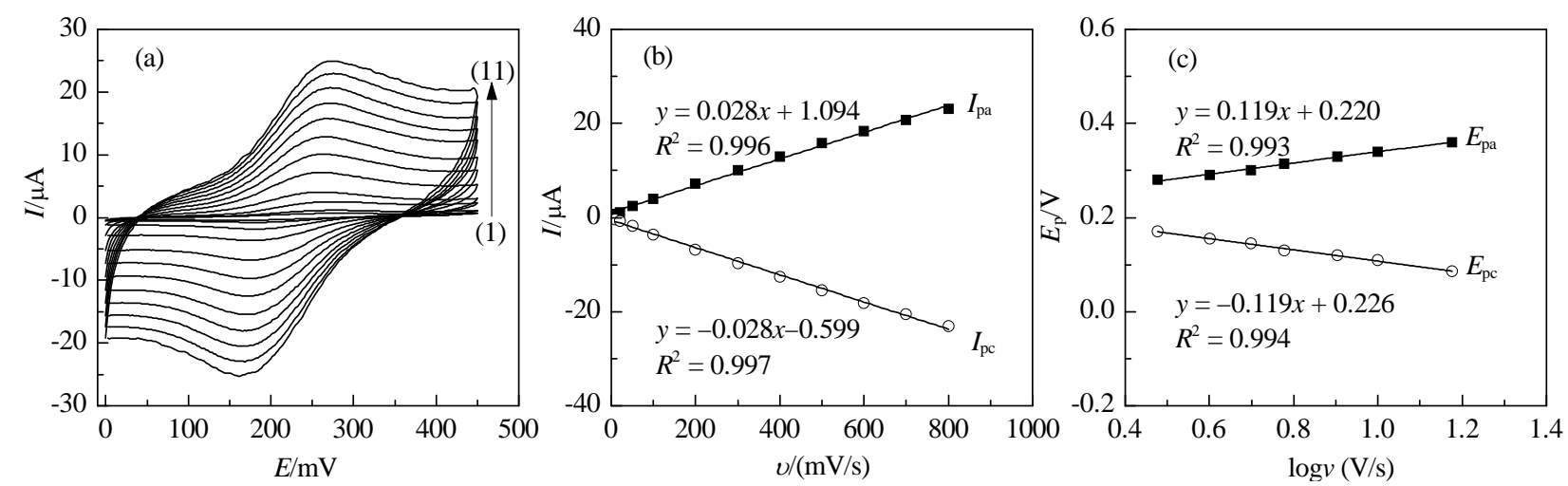

Fig. 1. (a) CVs of 5ADB-CNPE in $0.1 \mathrm{~mol} / \mathrm{L}$ PBS (pH 7.0) at scan rates of 10 (1), 20 (2), 50 (3), 100 (4), 200 (5), 300 (6), 400 (7), 500 (8), 600 (9), 700 (10), and $800 \mathrm{mV} / \mathrm{s}(11)$; (b) $I_{\mathrm{p}}$ vs. scan rate; (c) Variation of $E_{\mathrm{p}}$ versus the logarithm of high scan rates.
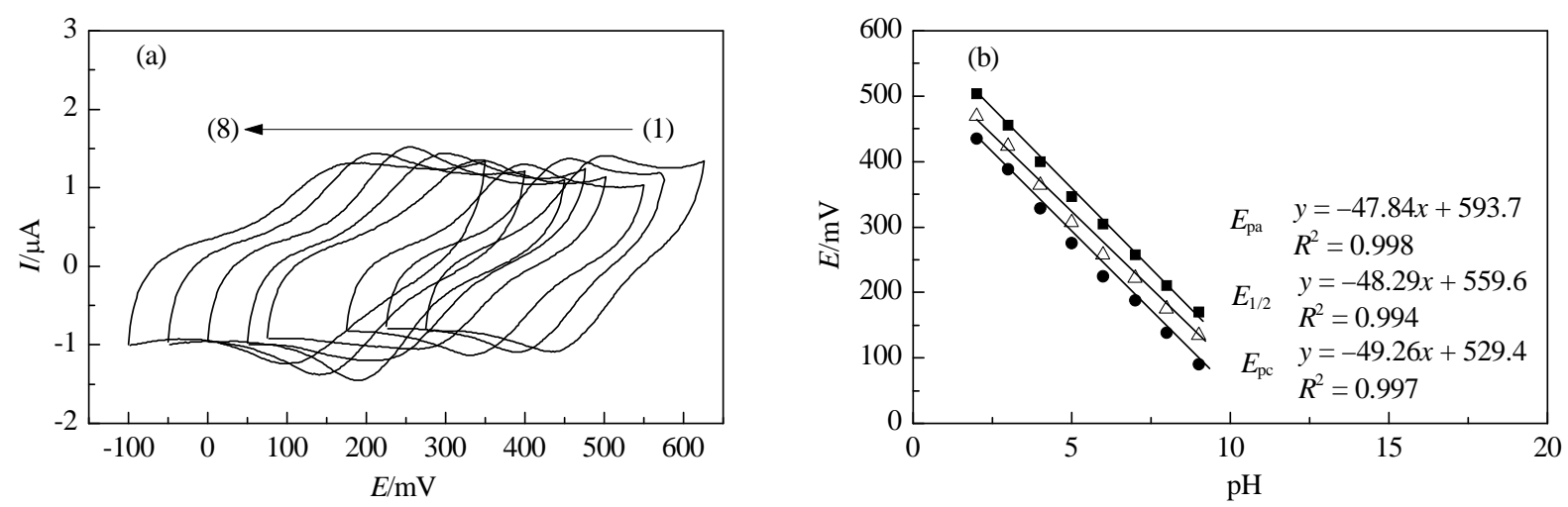

Fig. 2. (a) CVs of 5ADB-CNPE at a scan rate of $20 \mathrm{mV} / \mathrm{s}$ and pH of 2.0 (1), 3.0 (2), 4.0 (3), 5.0 (4), 6.0 (5), 7.0 (6), 8.0 (7), and 9.0 (8); (b) Plots of $E_{\mathrm{pa}}, E_{\mathrm{pc}}$, and $E_{1 / 2}$ vs. pH. 


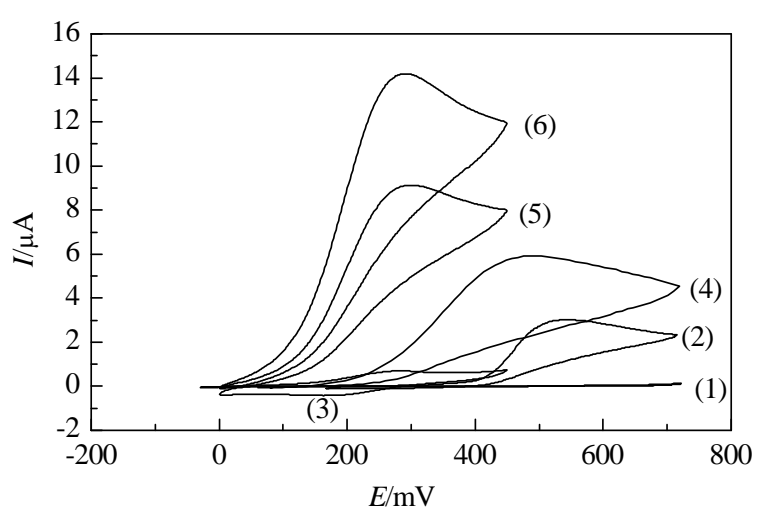

Fig. 3. CVs of unmodified CPE in $0.1 \mathrm{~mol} / \mathrm{L}$ PBS (pH 7.0) (1) and 0.4 $\mathrm{mmol} / \mathrm{L} \mathrm{AA} \mathrm{(2),} \mathrm{5ADB-CNPE} \mathrm{in} 0.1 \mathrm{~mol} / \mathrm{L} \mathrm{PBS}$ (3), CNPE in $0.4 \mathrm{mmol} / \mathrm{L}$ AA (4), 5ADB-CPE in $0.4 \mathrm{mmol} / \mathrm{L} \mathrm{AA} \mathrm{(5),} \mathrm{and} \mathrm{5ADB-CNPE} \mathrm{in} 0.4$ $\mathrm{mmol} / \mathrm{L} \mathrm{AA} \mathrm{(6).} \mathrm{In} \mathrm{all} \mathrm{cases} \mathrm{the} \mathrm{scan} \mathrm{rate} \mathrm{was} 10 \mathrm{mV} / \mathrm{s}$.

increasing pH. Figure 2(b) shows potential-pH diagrams constructed by plotting anodic, cathodic, and half-wave potentials as functions of $\mathrm{pH}$. The slopes of these plots are 47.84, 49.26, and $48.29 \mathrm{mV} / \mathrm{pH}$ for $E_{\mathrm{pa}}, E_{\mathrm{pc}}$, and $E_{1 / 2}$, respectively, indicating that the system obeys the Nernst equation with equal electron and proton transfer reaction [47].

\subsection{Electrocatalytic oxidation of $A A$ at a $5 A D B-C N P E$}

Figure 3 depicts the $\mathrm{CV}$ responses for the electrochemical oxidation of $0.4 \mathrm{mmol} / \mathrm{L} \mathrm{AA}$ at the unmodified CPE, CNPE, 5ADB-CPE, and 5ADB-CNPE. While the anodic peak potentials for AA oxidation at the CNPE and unmodified CPE are 500 and $560 \mathrm{mV}$, respectively, the corresponding potentials at both 5ADB-CNPE and 5ADB-CPE are $\sim 280 \mathrm{mV}$. These results indicate that the peak potential for AA oxidation at 5ADB-CNPE and 5ADB-CPE shift to a more negative potential by 220 and 280 $\mathrm{mV}$ compared with those of CNPE and unmodified CPE, respectively. However, 5ADB-CNPE shows much higher anodic peak current for the oxidation of AA than 5ADB-CPE, indicating that the combination of CNTs and 5ADB significantly improves the performance of the electrode toward AA oxidation. In fact, 5ADB-CNPE in the absence of AA exhibited a stable redox reaction (Fig. 3(3)) in $0.1 \mathrm{~mol} / \mathrm{L}$ PBS at pH 7.0. However, a large increase in the anodic peak current was observed in the presence of $0.4 \mathrm{mmol} / \mathrm{L} \mathrm{AA}$ (Fig. 3(6)), which is attributed to the strong electrocatalytic effect of 5ADB-CNPE towards AA [47].

The effect of scan rate on the electrocatalytic oxidation of $A A$ at 5ADB-CNPE was investigated by CV (Fig. 4(a)). The oxidation peak potential shifted to a more positive value with increasing scan rate, confirming the kinetic limitation of the electrochemical reaction. Also, a plot of peak height $\left(I_{\mathrm{p}}\right)$ vs. the square root of scan rate $\left(v^{1 / 2}\right)$ was linear in the range of $2-20 \mathrm{mV} / \mathrm{s}$, suggesting that at sufficient overpotential, the process is diffusion rather than surface controlled (Fig. 4(b)).

The Tafel slope $(b)$ can be obtained from the slope of a plot of $E_{\mathrm{p}}$ vs. $\log v$ using Eq. (2) [47]:

$$
E_{\mathrm{p}}=b / 2 \log v+\text { constant }
$$

The Tafel slope was found to be $0.14 \mathrm{~V}$ (Fig. 4(c)), which indicates that a one-electron transfer process is the rate-limiting step assuming a transfer coefficient $(\alpha)$ of about 0.58 .

\subsection{Chronoamperometric measurements}

Chronoamperometric measurements of AA at 5ADB-CNPE were carried out by setting the working electrode potential at $0.35 \mathrm{~V}$ at the first potential step and $0.05 \mathrm{~V}$ at second potential step vs. $\mathrm{Ag} / \mathrm{AgCl} / \mathrm{KCl}$ (3.0 mol/L) for various concentrations of AA in PBS (pH 7.0), as presented in Fig. 5. For an electroactive material (AA in this case) with a diffusion coefficient $D$, the current observed for the electrochemical reaction under mass transport-limited conditions can be described by the Cottrell equation [47]. Experimental plots of $I$ vs. $t^{-1 / 2}$ were drawn, and the best fits for different concentrations of AA were determined (Fig. 5(b)). The slopes of the resulting straight lines were then plotted against AA concentration (Fig. 5(c)). From the resulting slope and Cottrell equation, the mean value of $D$ was found to be $2.2 \times 10^{-6} \mathrm{~cm}^{2} / \mathrm{s}$.

Chronoamperometry can also be used to evaluate the catalytic rate constant, $k$, for the reaction between $\mathrm{AA}$ and 5ADB-CNPE according to the method of Galus [49]:

$$
I_{C} / I_{L}=\gamma^{1 / 2}\left[\pi^{1 / 2} \operatorname{erf}\left(\gamma^{1 / 2}\right)+\exp (-\gamma) / \gamma^{1 / 2}\right]
$$

where $I_{C}$ is the catalytic current of AA at $5 \mathrm{ADB}-\mathrm{CNPE}, I_{\mathrm{L}}$ is the limited current in the absence of $\mathrm{AA}$, and $\gamma=k C_{\mathrm{b}} t$ is the argument of the error function ( $C_{b}$ is the bulk concentration of $\left.A A\right)$. When $\gamma$ exceeds 2, the error function is almost equal to 1, so Eq. (3) can be reduced to:

$$
I_{C} / I_{L}=\pi^{1 / 2} \gamma^{1 / 2}=\pi^{1 / 2}(k C b t)^{1 / 2}
$$

where $t$ is the time elapsed. Equation (4) can be used to calcu-
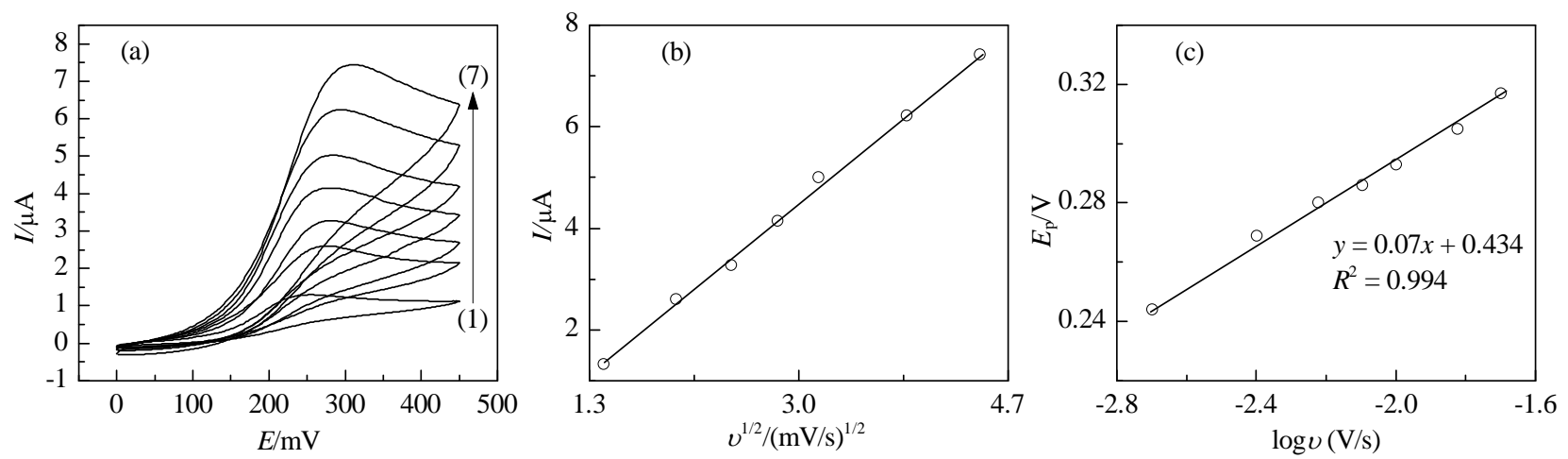

Fig. 4. (a) CVs of 5ADB-CNPE in $0.1 \mathrm{~mol} / \mathrm{L}$ PBS (pH 7.0) containing $10.0 \mu \mathrm{mol} / \mathrm{L} \mathrm{AA}$ at scan rates of 2 (1), 4 (2), 6 (3), 8 (4), 10 (5), 15 (6), and 20 mV/s (7); (b) Anodic peak current vs. $v^{1 / 2}$; (c) Anodic peak potential vs. $\log v$. 

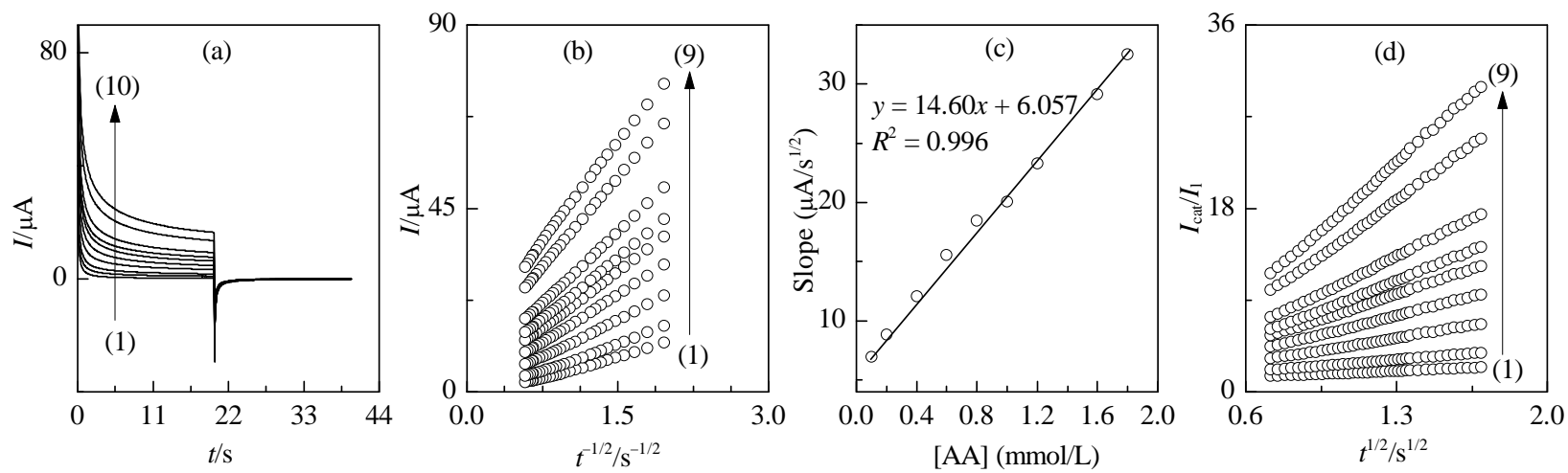

Fig. 5. (a) Chronoamperograms obtained at 5 ADB-CNPE in $0.1 \mathrm{~mol} / \mathrm{L}$ PBS (pH 7.0) for concentrations of AA of 0.0 (1), 0.1 (2), 0.2 (3), 0.4 (4), 0.6 (5), 0.8 (6), 1.0 (7), 1.2 (8), 1.6 (9), and $1.8 \mathrm{mmol} / \mathrm{L}(10)$; (b) Plots of $I v s . t^{-1 / 2}$ obtained from chronoamperograms (2)-(10) in (a); (c) Plot of the slope of the straight lines against AA concentration; (d) Dependence of $I_{\text {cat }} / I_{1}$ on $t^{1 / 2}$ derived from the data in chronoamperogram (2)-(10) in (a).

late $k$ of the catalytic process from the slope of $I_{C} / I_{L}$ vs. $t^{1 / 2}$ at a given AA concentration. The average value of $k$ was calculated to be $2.4 \times 10^{4} \mathrm{~L} /(\mathrm{mol} \cdot \mathrm{s})$.

\subsection{Electrocatalytic determination of $A A$}

The electrocatalytic peak current of AA oxidation at the surface of the modified electrode can be used to determine the concentration of AA in solution. Therefore, square wave voltammetry (SWV) experiments were performed using the modified electrode in PBS containing different concentrations of AA (Fig. 6). The mediated oxidation peak currents of AA at the surface of the modified electrode were proportional to the concentration of AA within the range $6.0 \times 10^{-7}-1.0 \times 10^{-3} \mathrm{~mol} / \mathrm{L}$ in the SWV measurements. The obtained detection limit $(3 \sigma)$ was $3.0 \times 10^{-7} \mathrm{~mol} / \mathrm{L}$.

\subsection{Simultaneous determination of $A A, A C$, and TRP}

The simultaneous determination of AA, AC, and TRP using a 5ADB-CNPE has not been reported, so the main objective of this study was to detect $\mathrm{AA}, \mathrm{AC}$, and TRP simultaneously using 5ADB-CNPE. This was achieved by simultaneously changing the concentrations of $\mathrm{AA}, \mathrm{AC}$, and TRP, and recording SWVs, as shown in Fig. 7. SWVs showed well-defined anodic peaks at potentials of 265,465 , and $780 \mathrm{mV}$, corresponding to the oxi-

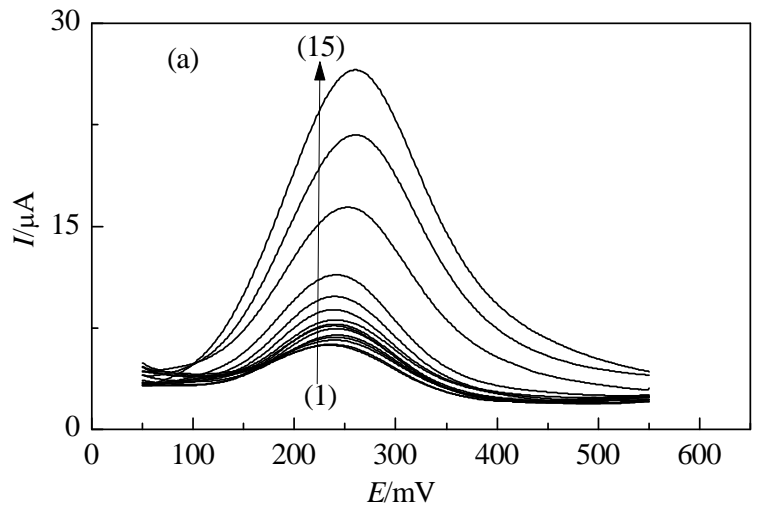

dation of $\mathrm{AA}, \mathrm{AC}$, and TRP, respectively. These peaks indicate that simultaneous determination of these compounds at 5ADB-CNPE is feasible.

The sensitivity of the modified electrode for the oxidation of AA was $0.019(\mu \mathrm{A} \cdot \mathrm{L}) / \mu \mathrm{mol}$, which is equal to that obtained in the absence of AC and TRP (see section 3.5). This indicates that the oxidation processes of these compounds at 5ADB-CNPE are independent and, therefore, simultaneous determination of their concentrations in mixtures without significant interference is possible.

\subsection{Sample analysis using 5ADB-CNPE}

The catalytic oxidation of AA by 5ADB-CNPE was also investigated using real samples. The concentration of AA in pharmaceutical samples, such as vitamin $\mathrm{C}$ ampoules and effervescent tablets, was determined by recording SWVs of 5ADB-CNPE in $0.1 \mathrm{~mol} / \mathrm{L} \mathrm{PBS} \mathrm{(pH} \mathrm{7.0)} \mathrm{containing} \mathrm{real} \mathrm{samples.}$

\subsubsection{Determination of the concentration of $A A$ in an ampoule}

AA from an ampoule $(1 \mathrm{ml})$ was diluted to $10 \mathrm{ml}$ with PBS (0.1 mol/l, pH 7.0) and then different amounts of the diluted solution were transferred into a series of volumetric flasks and diluted to $10 \mathrm{ml}$ with PBS. Each sample solution was transferred into an electrochemical cell and SWVs were recorded between 0.0 and $0.5 \mathrm{~V}$ at a scan rate of $10 \mathrm{mV} / \mathrm{s}$. Ipa was meas-

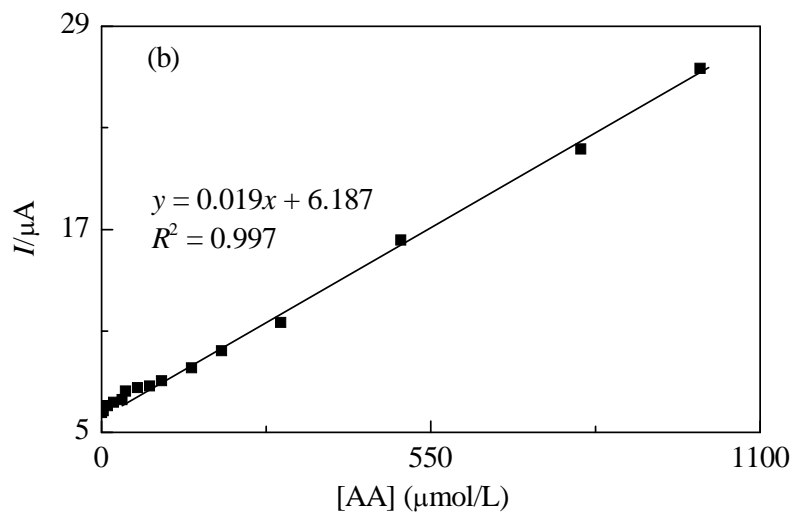

Fig. 6. (a) SWVs of 5ADB-CNPE in $0.1 \mathrm{~mol} / \mathrm{L}$ PBS (pH 7.0) containing different concentrations of AA. AA concentrations ( $\mu \mathrm{mol} / \mathrm{L})$ : (1) 0.6; (2) 2.5; (3) 10.0; (4) 20.0; (5) 35.0; (6) 40.0; (7) 60.0; (8) 80.0; (9) 100.0; (10) 150.0; (11) 200.0; (12) 300.0; (13) 500.0; (14) 800.0; (15) 1000.0. (b) A plot of electrocatalytic peak current as a function of AA concentration in the range of $0.6-1000.0 \mu \mathrm{mol} / \mathrm{L}$. 

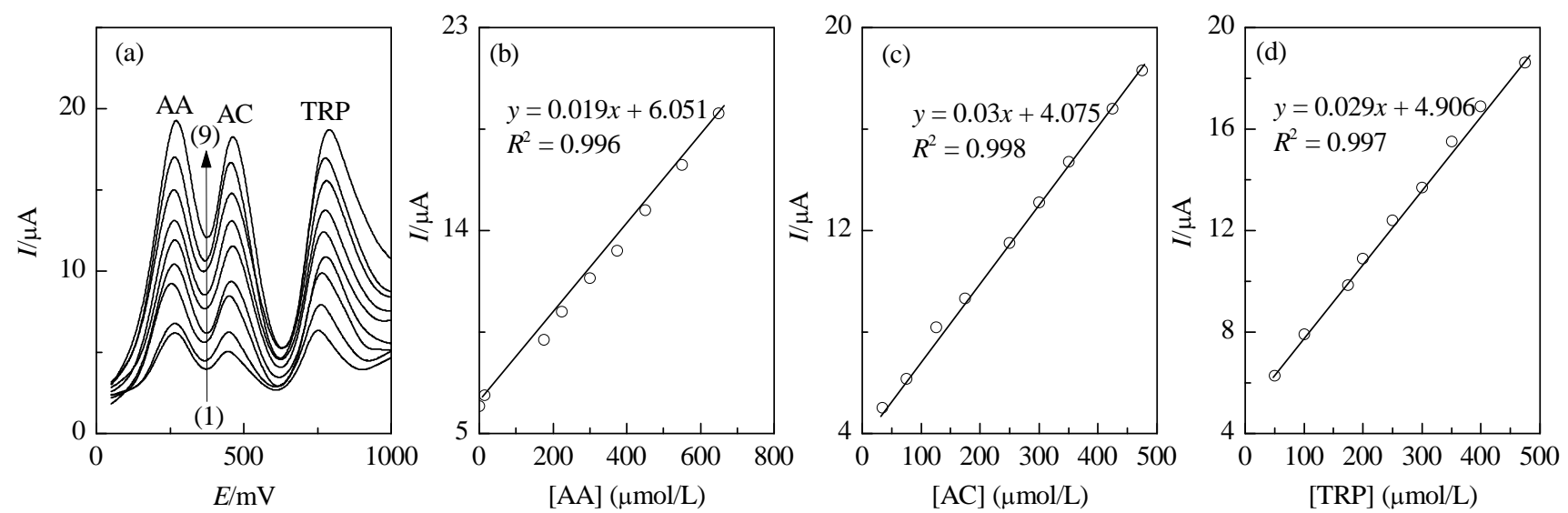

Fig. 7. (a) SWVs of 5 ADB-CNPE in $0.1 \mathrm{~mol} / \mathrm{L}$ PBS (pH 7.0) containing different concentrations of AA, AC, and TRP. Concentrations of AA+AC+TRP ( $\mu \mathrm{mol} / \mathrm{L}):(1) 0.6+35.0+50.0$; (2) $15.0+75.0+100.0$; (3) $175.0+125.0+175.0$; (4) $225.0+175.0+200.0$; (5) 300.0 + 250.0 + 250.0; (6) 375.0 + $300.0+300.0$; (7) $450.0+350.0+350.0$; (8) $550.0+425.0+400.0$; (9) $650.0+475.0+475.0$. (b) $-\left(\mathrm{d}\right.$ ) are plots of $I_{\mathrm{p}}$ vs. concentration of AA, AC, and TRP, respectively.

ured at the oxidation potential of AA and its concentration was obtained from the calibration plot. This procedure was repeated three times for each sample. The average amount of AA in the ampoule was determined to be $500.5 \mathrm{mg}$ AA per $5 \mathrm{ml}$, consistent with the value on the label ( $500 \mathrm{mg}$ AA per $5 \mathrm{ml}$ ). Also, different amounts of the diluted AA solutions together with standard AC and TRP solutions were added to a series of volumetric flasks and diluted to $10 \mathrm{ml}$ with PBS. SWVs were recorded and the anodic peak currents for each of AA, AC, and TRP were measured at their own oxidation potentials. According to the results listed in Table 1, the concentrations of AA, AC, and TRP were accurately determined with high reproducibility, which indicates that the sensor can be used to analyze these compounds with no significant interference.

\subsubsection{Determination of the amount of AA in effervescent tablets}

To evaluate the analytical applicability of 5ADB-CNPE, it was also used to determine the amount of AA in effervescent tablets. Based on the repeated SWV responses $(n=3)$ of the diluted analytes and samples that were spiked with specified concentrations of $\mathrm{AA}$, measurements were made to determine the amount of AA in effervescent tablets. The results presented in Table 2 show that the RSD and the recovery rates of the spiked samples were acceptable. The average amount of AA in each effervescent tablet was found to be $553.7 \mathrm{mg}$, which agrees with that reported on the label (550 mg). Thus, the modified electrode can be used to efficiently determine the amounts of AA, AC, and TRP in effervescent tablets without significant interference from the other compounds.

\section{Conclusions}

A novel modified CNPE was constructed to detect AA. The results show that the oxidation of $\mathrm{AA}$ was catalyzed at $\mathrm{pH} 7.0$, and the peak potential of AA was shifted to less positive potential at 5ADB-CNPE than at an electrode lacking 5ADB.

Table 1

Determination of AA, AC, and TRP in an ampoule containing AA.

\begin{tabular}{|c|c|c|c|c|c|c|c|c|c|c|c|}
\hline \multirow{2}{*}{$\begin{array}{l}\text { AA } \\
\text { ampoule } \\
(\mu \mathrm{mol} / \mathrm{L})\end{array}$} & \multirow{2}{*}{$\begin{array}{c}\mathrm{AC} \\
\text { added } \\
(\mu \mathrm{mol} / \mathrm{L})\end{array}$} & \multirow{2}{*}{$\begin{array}{c}\text { TRP } \\
\text { added } \\
(\mu \mathrm{mol} / \mathrm{L})\end{array}$} & \multicolumn{3}{|c|}{$\mathrm{AA}$} & \multicolumn{3}{|c|}{$\mathrm{AC}$} & \multicolumn{3}{|c|}{ TRP } \\
\hline & & & $\begin{array}{c}\text { Found } \\
(\mu \mathrm{mol} / \mathrm{L})\end{array}$ & $\begin{array}{c}\text { Recovery } \\
(\%)\end{array}$ & $\begin{array}{l}\text { RSD } \\
(\%)\end{array}$ & $\begin{array}{c}\text { Found } \\
(\mu \mathrm{mol} / \mathrm{L})\end{array}$ & $\begin{array}{c}\text { Recovery } \\
(\%)\end{array}$ & $\begin{array}{l}\text { RSD } \\
(\%)\end{array}$ & $\begin{array}{c}\text { Found } \\
(\mu \mathrm{mol} / \mathrm{L})\end{array}$ & $\begin{array}{c}\text { Recovery } \\
(\%)\end{array}$ & $\begin{array}{l}\text { RSD } \\
(\%)\end{array}$ \\
\hline 100.0 & 0.0 & 0.0 & 103.0 & 103.0 & 1.5 & - & - & - & - & - & - \\
\hline 100.0 & 30.0 & 30.0 & 99.7 & 99.7 & 1.6 & 29.2 & 97.3 & 1.8 & 30.1 & 100.3 & 3.5 \\
\hline 150.0 & 0.0 & 0.0 & 149.6 & 99.7 & 2.8 & - & - & - & - & - & - \\
\hline 150.0 & 50.0 & 50.0 & 150.2 & 100.1 & 1.3 & 50.7 & 101.4 & 3.2 & 51.0 & 102.0 & 1.3 \\
\hline 230.0 & 0.0 & 0.0 & 228.4 & 99.3 & 1.5 & - & - & - & - & - & - \\
\hline 230.0 & 100.0 & 200.0 & 227.7 & 99.0 & 1.8 & 100.9 & 100.9 & 1.7 & 196.3 & 98.1 & 1.1 \\
\hline
\end{tabular}

RSD: relative standard deviations.

Table 2

Determination of the amounts of $\mathrm{AA}, \mathrm{AC}$, and TRP in AA tablets.

\begin{tabular}{|c|c|c|c|c|c|c|c|c|c|c|c|}
\hline \multirow{2}{*}{$\begin{array}{l}\mathrm{AA} \\
\text { tablet } \\
(\mu \mathrm{mol} / \mathrm{L})\end{array}$} & \multirow{2}{*}{$\begin{array}{c}\mathrm{AC} \\
\text { added } \\
(\mu \mathrm{mol} / \mathrm{L})\end{array}$} & \multirow{2}{*}{$\begin{array}{c}\text { TRP } \\
\text { added } \\
(\mu \mathrm{mol} / \mathrm{L})\end{array}$} & \multicolumn{3}{|c|}{ AA } & \multicolumn{3}{|c|}{$\mathrm{AC}$} & \multicolumn{3}{|c|}{ TRP } \\
\hline & & & $\begin{array}{c}\text { Found } \\
(\mu \mathrm{mol} / \mathrm{L})\end{array}$ & $\begin{array}{c}\text { Recovery } \\
(\%)\end{array}$ & $\begin{array}{l}\text { RSD } \\
(\%)\end{array}$ & $\begin{array}{c}\text { Found } \\
(\mu \mathrm{mol} / \mathrm{L})\end{array}$ & $\begin{array}{c}\text { Recovery } \\
(\%)\end{array}$ & $\begin{array}{l}\text { RSD } \\
(\%)\end{array}$ & $\begin{array}{c}\text { Found } \\
(\mu \mathrm{mol} / \mathrm{L})\end{array}$ & $\begin{array}{c}\text { Recovery } \\
(\%)\end{array}$ & $\begin{array}{l}\text { RSD } \\
(\%)\end{array}$ \\
\hline 50.0 & 0.0 & 0.0 & 49.5 & 99.0 & 1.89 & - & - & - & - & - & - \\
\hline 50.0 & 70.0 & 50.0 & 50.1 & 100.2 & 2.4 & 67.3 & 96.1 & 2.3 & 50.8 & 101.6 & 2.8 \\
\hline 100.0 & 0.0 & 0.0 & 102.1 & 102.1 & 1.1 & - & - & - & - & - & - \\
\hline 100.0 & 100.0 & 80.0 & 99.4 & 99.4 & 3.2 & 100.1 & 100.1 & 1.6 & 80.2 & 100.2 & 2.1 \\
\hline 200.0 & 0.0 & 0.0 & 198.5 & 99.2 & 1.8 & - & - & - & - & - & - \\
\hline 200.0 & 130.0 & 150.0 & 204.3 & 102.1 & 2.4 & 128.9 & 99.1 & 1.5 & 147.1 & 98.1 & 1.6 \\
\hline
\end{tabular}




\section{Graphical Abstract}

Chin. J. Catal., 2013, 34: 1098-1104 doi: 10.1016/S1872-2067(12)60544-0

\section{Voltammetric determination of ascorbic acid in the presence of acetaminophen and} tryptophan using an improved carbon nanotube paste electrode

Hadi BEITOLLAHI*, Somayeh MOHAMMADI

Graduate University of Advanced Technology, Iran

Payame Noor University, Iran

A new electrochemical sensor based on a modified carbon nanotube paste electrode is constructed for simultaneous determination of ascorbic acid (AA), acetaminophen (AC), and tryptophan (TRP).

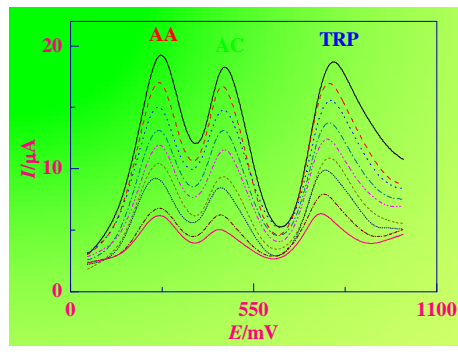

5ADB-CNPE exhibited a linear response over a wide concentration range of $6.0 \times 10^{-7}-1.0 \times 10^{-3} \mathrm{~mol} / \mathrm{L}$ with a detection limit of $3.0 \times 10^{-7} \mathrm{~mol} / \mathrm{L}$. This modified electrode separated the anodic oxidation peak potentials of AA, AC, and TRP in a well defined manner, allowing the concentrations of $\mathrm{AA}, \mathrm{AC}$, and TRP to be determined without apparent intermolecular effects. The values of $k, D$, and $\alpha$ for 5ADB-CNPE were found to be $2.4 \times 10^{4}$ $\mathrm{L} /(\mathrm{mol} \cdot \mathrm{s}), 2.2 \times 10^{-6} \mathrm{~cm}^{2} / \mathrm{s}$, and 0.58 , respectively. 5ADB-CNPE was also successfully used for determination of $\mathrm{AA}, \mathrm{AC}$, and TRP in actual samples.

\section{References}

[1] Beitollahi H, Karimi-Maleh H, Khabazzadeh H. Anal Chem, 2008, 80: 9848

[2] Raoof J B, Ojani R, Baghayeri M. Chin J Catal (催化学报), 2011, 32: 1685

[3] Salazar P, Martin M, O'Neill RD, Roche R, Gonzalez-Mora J L. Colloids Surf B, 2012, 92: 180

[4] Raoof J B, Ojani R, Beitollahi H. Electroanalysis, 2007, 19: 1822

[5] Lü W X, Shi K Y, Li L, Shao S Z. Microchim Acta, 2010, 170: 91

[6] Raoof J B, Ojani R, Beitollahi H, Hosseinzadeh R. Electroanalysis, 2006, 18: 1193

[7] Xi X, Ming L, Liu J. J Appl Electrochem, 2010, 40: 1449

[8] Beitollahi H, Raoof J B, Hosseinzadeh R. Electroanalysis, 2011, 23: 1934

[9] Ensafi A A, Lotfi M, Karimi-Maleh H. Chin J Catal (催化学报), 2012, 33: 487

[10] Iijima S. Nature, 1991, 354: 56

[11] Deng X Y, Zhang D Y, Wang X, Yuan X X, Ma Z F. Chin J Catal, 2008, 29: 519

[12] Beitollahi H, Sheikhshoaie I. Electrochim Acta, 2011, 56: 10259

[13] Liu X H, Li L, Zhao X P, Lu X Q. Colloids Surf B, 2010, 81: 344

[14] Zhang H F, Meng Z C, Wang Q, Zheng J B. Sens Actuators B, 2011, 158: 23

[15] Rastakhiz N, Beitollahi H, Kariminik A, Karimi F. J Molec Liq, 2012, 172: 66

[16] Kuralay F, Vural T, Bayram C, Denkbas E B, Abaci S. Colloids Surf B, 2011, 87: 18

[17] Beitollahi H, Sheikhshoaie I. Anal Methods, 2011, 3: 1810

[18] Nishikimi M, Yagi K. Subcell Biochem, 1996, 25: 17

[19] Padayatty S J, Katz A, Wang Y, Eck P, Kwon O, Lee J, Chen S, Corpe C, Dutta A, Dutta S K, Levine M. J Am Coll Nutr, 2003, 22: 18

[20] Arrigoni O, de tullio M C. Biophys Acta, 2002, 1569: 1

[21] Keller K L, Fenske N A. J Am Acad Dermatol, 1998, 39: 611

[22] Qiu S Y, Gao S, Liu Q D, Lin Z Y, Qiu B, Chen G N. Biosens Bioelectron
2011, 26: 4326

[23] Shekhovtsova T N, Muginova S V, Luchinina J A, Galimova A Z. Anal Chim Acta, 2006, 573: 125

[24] Ensafi A A, Karimi-Maleh H, Mallakpour S. Electroanalysis, 2012, 24: 666

[25] Hosseinzadeh R, Sabzi R E, Ghasemlu K. Colloids Surf B, 2009, 68: 213

[26] Ammam M, Easton E B. Electrochim Acta, 2011, 56: 2847

[27] Gobal F, Majari-Kasmaee L. Chin J Catal (催化学报), 2012, 33: 267

[28] Anker A. In: Marx J Ed. Clinical Toxicology. Philadelphia: W.B. Saunders Company, 2001

[29] Clayton B D, Stock Y N. Basic Pharmacology for Nurses. St Louis: Mosby Inc., Harcourt Health Sciences Company, 2001

[30] Kristensen D M, Hass U, Lesné L, Lottrup G, Jacobsen P R, Desdoits-Lethimonier C, Boberg J, Petersen J H, Toppari J, Jensen T K, Brunak S, Skakkebaek N E, Nellemann C, Main K M, Jégou B, Leffers H. Hum Reprod, 2010, 25: 235

[31] Mazloum-Ardakani M, Beitollahi H, Sheikh Mohseni M A, Benvidi A, Naeimi H, Nejati-Barzoki M, Taghavinia N. Colloids Surf B, 2010, 76: 82

[32] Beitollahi H, Raoof J B, Hosseinzadeh R. Talanta, 2011, 85: 2128

[33] Shayani-Jam H, Nematollahi D. Chem Commun, 2010, 46: 409

[34] Beitollahi H, Sheikhshoaie I.J Electroanal Chem, 2011, 661: 336

[35] Raoof J B, Baghayeri M, Ojani R. Colloids Surf B, 2012, 95: 121

[36] Beitollahi H, Mohadesi A, Mohammadi S, Akbari A. Electrochim Acta, 2012, 68: 220

[37] Horwitt M K, Harvey C C, Rothwell W S, Cutler J L, Haffron D. J Nutr, 1956, 60: 1

[38] Coppen A. BrJ Psychiatry, 1967, 113: 1237

[39] Reiter R J. Exp Gerontol, 1995, 30: 199

[40] Akhgar M R, Beitollahi H, Salari M, Karimi-Maleh H, Zamanid H. Anal Methods, 2012, 4: 259

[41] Huang K J, Xu C X, Xie W Z, Wang W. Colloids Surf B, 2009, 74: 167

[42] Mirrahimi F, Taher M A, Beitollahi H, Hosseinzadeh R. Appl Organometal Chem, 2012, 26: 194

[43] Tang X F, Liu Y, Hou H Q, You T Y. Talanta, 2010, 80: 2182

[44] Grundmann U, Wçrnle C, Biedler A, Kreuer S, Wrobel M, Wilhelm W. Anesth Analg, 2006, 103: 217

[45] http://www.umm.edu/altmed/articles/vitamin-c-000339.htm; Aug. 25, 2011

[46] Wu F C, Tanoue E. Anal Sci, 2001, 17: 1063

[47] Bard A J, Faulkner L R. Electrochemical Methods Fundamentals and Applications, 2nd ed. New York: Wiley, 2001

[48] Laviron E. J Electroanal Chem, 1979, 101: 19

[49] Galus Z. Fundamentals of Electrochemical Analysis. NewYork: Ellis Horwood, 1976 